Andreas Köhler

\title{
Eingriffsnormen - Der »unfertige Teil« des europäischen IPR
}

ANDREAS KÖHLER

Eingriffsnormen Der „unfertige Teil“ des europäischen IPR

Max-Planc-lnstitu sches und int

Studien zum ausländischen

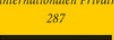

Mohr Siebeck

2013. XXI, 355 Seiten. StudIPR 287

ISBN 978-3-16-152532-2

DOI 10.1628/978-3-16-152532-2

eBook PDF 89,00€

ISBN 978-3-16-152531-5

fadengeheftete Broschur $89,00 €$
Mit Erlass der Verordnungen zum IPR der vertraglichen und außervertraglichen Schuldverhältnisse wurde der Problematik der sog. »Eingriffsnormen« eine europäischeDimension gegeben, die Andreas Köhler einer umfassenden und neue Wege beschreitenden Analyse unterzieht. Er kommt hierbei - entgegen der herkömmlichen Auffassung - zu dem Schluss, dass der auf in- und ausländische Eingriffsnormen bezogene kollisionsrechtliche Anwendungsbefehl nunmehr vollumfänglich europäischem Recht zu entnehmen ist. Auf dieser Grundlage errichtet er ein konsequentes System der Eingriffsnormen, welches eine kohärente kollisionsrechtliche Behandlung solcher Bestimmungen im europäischen IPR unter Beachtung des europäischen Entscheidungseinklangs ermöglicht. Wichtige Konsequenzen aus dem im Rahmen seiner Arbeit entwickelten Ansatz sind eine vollständigen Prüfungskompetenz des EuGH hinsichtlich des auf in- und ausländische Eingriffsnormen bezogenen kollisionsrechtlichen Anwendungsbefehls sowie eine umfassende Anwendungspflicht dritt- und mitgliedstaatlicher Eingriffsnormen.

Andreas Köhler Geboren 1983; Studium der Rechtswissenschaften in Tübingen; 2009-2011 Akademischer Mitarbeiter am Lehrstuhl für Bürgerliches Recht, Internationales Privatrecht und Rechtsvergleichung der Universität Tübingen; seit 2011 Rechtsreferendar am LG Passau (OLG-Bezirk München) und Wissenschaftlicher Mitarbeiter am Lehrstuhl für Bürgerliches Recht, Internationales Privatrecht und Rechtsvergleichung der Universität Passau; 2012 Promotion.
Jetzt bestellen:

https://mohrsiebeck.com/buch/eingriffsnormen-der-unfertige-teil-des-europaeischen-ipr-9783161525322?no_cache=1 order@mohrsiebeck.com

Telefon: +49 (0)7071-923-17

Telefax: $+49(0) 7071-51104$ 